\title{
Aspectos Moleculares da Tumorigênese Hipofisária
}

\begin{abstract}
RESUMO
Os tumores hipofisários, adenomas em sua quase totalidade, são de ocorrência freqüente, representando $10 \%$ a $15 \%$ de todas as neoplasias intracranianas. Estas lesões são classificadas em microadenomas $(<10 \mathrm{~mm}$ ) ou macroadenomas ( $>10 \mathrm{~mm}$ ) e como secretoras ou quiescentes (não-funcionantes). Estes tumores são capazes de secretar, de maneira autônoma, os hormônios adenohipofisários, como o hormônio de crescimento $(\mathrm{GH})$, a prolactina (PRL), o hormônio adrenocorticotrófico (ACTH), o hormônio tireotrófico (TSH), o hormônio folículo estimulante (FSH) e o hormônio luteinizante (LH). A ocorrência de metástase, caracterizando um carcinoma hipofisário, é bastante rara, mas são relativamente comuns tumores de comportamento agressivo que exibem sinais de invasão local. Embora a sua patogênese ainda não seja plenamente caracterizada, muitos mecanismos moleculares envolvidos na tumorigênese hipofisária já foram desvendados. Nesta revisão, serão descritos avanços consideráveis realizados na última década relativos à compreensão dos fatores envolvidos na progressão tumoral, incluindo a participação de oncogenes, supressores tumorais e fatores de crescimento. (Arq Bras Endocrinol Metab. 2008; 52/4:599-610)
\end{abstract}

Descritores: Adenomas hipofisários; Tumorigênese; Oncogenes; Supressores tumorais.

\section{ABSTRACT}

\section{Molecular Aspects of Pituitary Tumorigenesis.}

Pituitary tumors, almost invariably adenomas, are of frequent occurrence, accounting for $10 \%$ to $15 \%$ of all the intracranial neoplasm. They are classified as microadenomas $(<10 \mathrm{~mm})$ or macroadenomas $(>10 \mathrm{~mm})$ and as secreting or clinically non-secreting (or not functioning) adenomas. These tumors are autonomously capable to release pituitary hormones such as the growth hormone $(\mathrm{GH})$, prolactin (PRL), adrenocorticotropic hormone (ACTH), thyroid stimulating hormone (TSH), follicle-stimulating hormone (FSH) and luteinizing hormone (LH). The occurrence of metastases, characterizing a pituitary carcinoma, is exceedingly rare. However tumors with aggressive behavior, leading to local invasion, are relatively common. Although the pathogenesis of pituitary tumors is fully characterized, many molecular mechanisms of pituitary tumorigenesis had already been revealed. This review intents to describe advances in the understanding of the involved advances that have been made in the last decade concerning pituitary tumors progression, including the participation of oncogenes, tumor suppressor genes and growth factors. (Arq Bras Endocrinol Metab. 2008; 52/4:599-610)

Keywords: Pituitary tumors; Tumorigenesis; Oncogenes; Suppressor tumor.

\section{revisão}

\author{
EMILIA M. PINTO \\ MARCELlo D. Bronstein
}

Laboratório de Hormônios e Genética Molecular LIM/42 da Disciplina de Endocrinologia e Metabologia do Hospital das Clínicas da Faculdade de Medicina da Universidade de São Paulo (HC-FMUSP), SP, Brasil (EMP); Unidade de Neuroendocrinologia da Disciplina de Endocrinologia do HC-FMUSP, São Paulo, SP, Brasil (MDB).

Recebido em 28/08/2007

Aceito em 3/04/2008 


\section{INTRODUÇÃO}

E MBORA OS TUMORES HIPOFISÁRIOS sejam de ocorrência freqüente, representando $10 \%$ a $15 \%$ de todas as neoplasias intracranianas, os mecanismos que levam ao desenvolvimento destas lesões ainda não são bem caracterizados (1). A tumorigênese é o processo constituído de múltiplas etapas, que determinam a transformação progressiva de células normais em células malignas (2). A proliferação celular descontrolada e o aumento de viabilidade sobre clones normais são características marcantes dos tumores e ocorrem como conseqüência de alterações genotípicas e fenotípicas das células (3). Estudos envolvendo a progressão tumoral em populações humanas indicam que, em média, quatro a seis eventos, com participação ativa de genes relacionados ao processo de imortalização e outros envolvidos na regulação do ciclo celular, atuam na formação do tumor (4).

A imortalização celular pode ser obtida pelo aumento da expressão da telomerase, proteína responsável pela produção de seqüências repetitivas de nucleotídeos que recobrem os telômeros, extremidades distais dos cromossomos, que normalmente encurtam em cada replicação celular (5). A manutenção do comprimento do telômero é um mecanismo-chave para a imortalidade celular (6) e representa um mecanismo potencial que capacita as células a ultrapassarem pontos críticos durante os estágios da transformação neoplásica (7). Outro mecanismo capaz de tornar as células imortalizadas envolve agentes virais que podem transformar as células infectadas por causa da liberação de proteínas virais que interferem nos mecanismos de multiplicação celular (8).

\section{ORIGEM CLONAL}

Tumores hipofisários são compostos por uma população celular de origem monoclonal $(9,10)$. A origem clonal dos tumores pode ser analisada por meio do mecanismo de inativação de um dos cromossomos X em células somáticas de fêmeas (11). Em cada célula somática feminina, um cromossomo X é inativado permanecendo condensado e aparecendo na interfase como o corpúsculo de Barr (cromatina sexual), enquanto o outro permanece ativo. $\mathrm{O} X$ inativo pode ser de origem tanto paterna quanto materna, nas diferentes células da fêmea. Mas, após a "decisão” de qual dos X será inativado em uma determinada célula, todas as células descendentes terão $\mathrm{o}$ mesmo $\mathrm{X}$ inativado. A inativação ocorre ao acaso, mas é fixa. Assim, em um tumor deri- vado de uma única célula somática, todas as células tumorais mostrarão o mesmo modelo de inativação do cromossomo X, sendo, portanto de origem monoclonal. Para se determinar a origem clonal do tumor é necessário identificar um gene no cromossomo X que seja polimórfico, em outras palavras, que possa diferir entre o X de origem materna e o X de origem paterna. São bastante estudados os genes HPRT (bypoxanthine phosphoribosyl transferase), o gene PGK (phosphoglycerate kinase) e o gene $\mathrm{AR}$ (androgen receptor).

\section{Ciclo Celular}

O processo de divisão celular deve garantir a correta distribuição dos cromossomos entre as células filhas, processo este denominado mitose (Figura 1). O período entre duas divisões mitóticas define o ciclo celular somático. A coordenação precisa das diferentes fases do ciclo celular é essencial a todos os organismos eucariontes. $\mathrm{O}$ intervalo entre o final de uma divisão mitótica e o início de outra é chamado interfase. Este período é classicamente dividido em três estágios: Gl (Gapl), S (synthesis) e G2 (Gap2). A fase em que as células estão temporária ou permanentemente fora do ciclo celular (quiescentes) é denominada G0. Durante o estágio Gl, as células aumentam em tamanho, sintetizam RNA e proteínas. Um mecanismo importante de controle do ciclo celular é ativado durante este período (Gl checkpoint) para certificar que todo o material para a síntese de DNA esteja pronto (12). Nutrientes, mitógenos e fatores de crescimento extracelulares induzem a transcrição de genes que são necessários para a síntese de DNA e a célula passa para o estágio seguinte, no qual ocorre a replicação do DNA (fase S). Durante o intervalo entre a síntese de DNA e a mitose (G2), a célula continua a crescer e sintetizar novas proteínas. Ao final deste intervalo, outro mecanismo de controle do ciclo celular (G2 checkpoint) verifica a necessidade de reparo dos erros da replicação do DNA antes da célula entrar em mitose. A perda do controle checkpoint resulta instabilidade genômica, acúmulo de lesões no DNA e proliferação celular não controlada, fenômenos que têm sido relacionados à progressão tumoral (12).

Participam desse processo proteínas denominadas ciclinas, em que durante o curso do ciclo celular possuem período de síntese crescente seguido por outro de rápida degradação, e as cinases que quando ativadas por ciclinas (CDKs) fosforilam as moléculas necessárias para a divisão celular. A ação das CDKs é regulada negativa- 


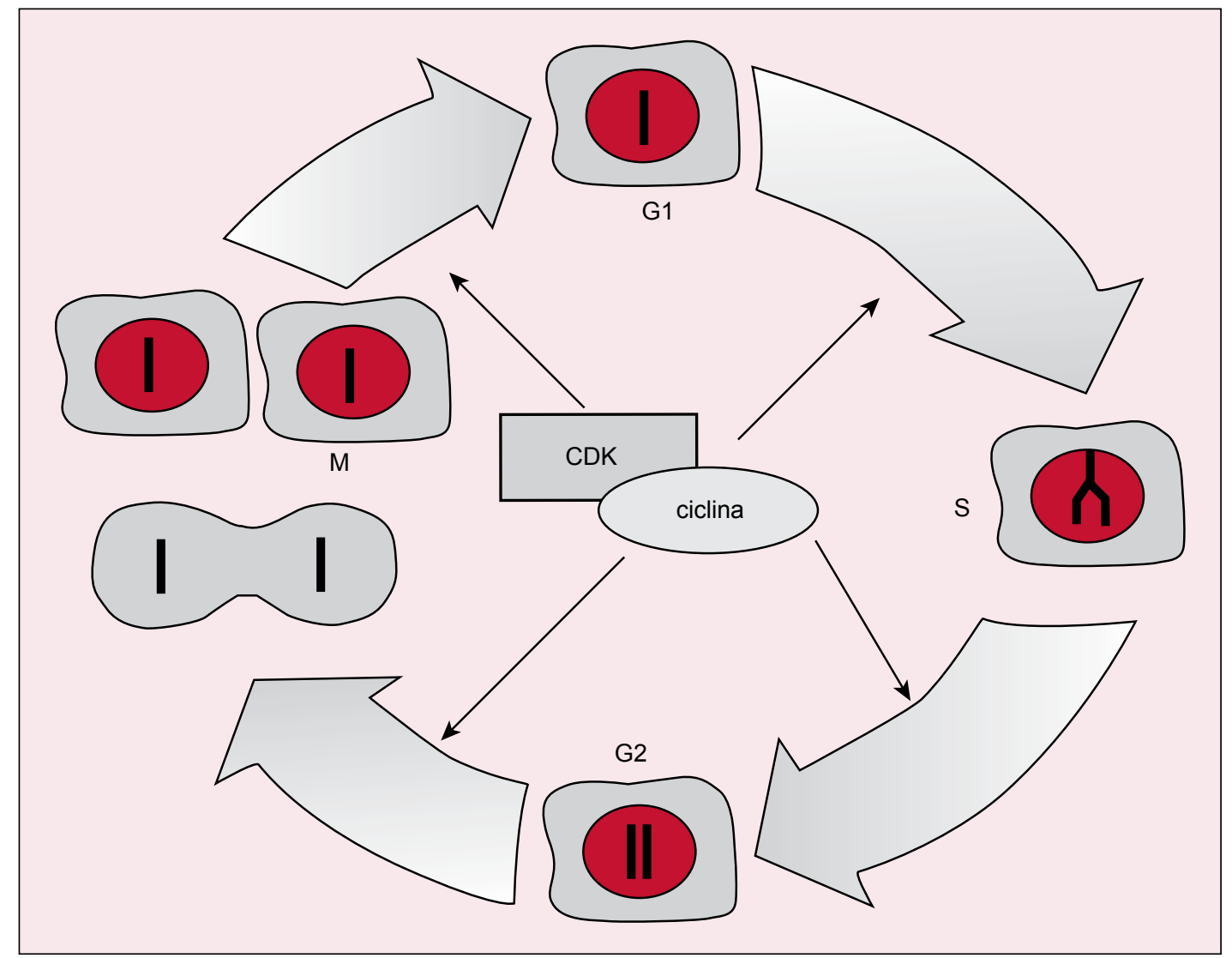

Figura 1. Representação esquemática do ciclo celular. G1: neste estágio as células aumentam em tamanho, sintetizam RNA e proteínas. Nutrientes, mitógenos e fatores de crescimento extracelulares induzem a transcrição de genes que são necessários para a síntese de DNA e a célula passa para o estágio seguinte, no qual ocorre a replicação do DNA (fase S). Durante o intervalo entre a síntese de DNA e a mitose (G2), a célula continua a crescer e sintetizar novas proteínas. Os mecanismos de checkpoint verificam a necessidade de reparo dos erros da replicação do DNA antes de a célula entrar em mitose (M). Todo o ciclo é regulado ordenadamente por atividade das ciclinas e das CDKs.

mente pelas CDKIs, proteínas que impedem a formação do complexo ativo ciclina/CDK. Entre estes inibidores destacam-se as proteínas p27, p21 e p16.

Entre os períodos $\mathrm{Gl} / \mathrm{S}$ e $\mathrm{G} 2 / \mathrm{M}$, a produção da proteína $\mathrm{P} 53$, que atua na transcrição do gene codificante da proteína p21 (CDKI), é ativada (13). A proteí-na P53 não é necessária para a progressão do ciclo celular, sendo, no entanto, importante regulador (checkpoint) durante a progressão Gl-S. Radiação ultravioleta, oncogenes e substâncias químicas lesivas ao DNA ativam proteínas, como ATM, Chkl e Chk2, que fosforilam P53 em sítios da região amino-terminal. Uma vez ativada, a proteína P53 induz ao aumento da expressão da proteína $\mathrm{p} 21^{\mathrm{Cip} / \mathrm{Kip}}$, um inibidor do complexo ciclinaquinase (14), e as células sofrem, então, um bloqueio nesta fase para que seja efetivado o reparo do DNA (15). Este bloqueio é de fundamental importância para permitir o reparo do DNA danificado antes que ocorra sua duplicação na fase $S$. Durante a divisão celular o alinhamento dos cromossomos metafásicos deve ser devidamente processado. Caso todos os cromossomos não estejam ligados ao fuso mitótico, as células filhas não serão idênticas. Como resultados dessa instabilidade, ocorrem ganhos e perdas cromossômicas, bem como rearranjos e amplificações de determinadas regiões. Estas alterações podem ser observadas por métodos citogenéticos, desde cariótipo propriamente dito até técnicas mais sofisticadas como FISH (fluorescence in-situ bybridization), estudos de marcadores polimórficos e CGH (comparative genome hibridization). A técnica de 
CGH permite avaliar regiões cromossômicas que sofreram deleções ou amplificações, por meio da hibridização do DNA tumoral versus um DNA controle (sangue periférico) em uma lâmina contendo preparações de cariótipo humano normal em metáfase, assim, admite-se que regiões cromossômicas que sofrem amplificações devam conter potenciais oncogenes, e as que sofreram deleções, genes supressores tumorais.

Alterações no número de cromossomos não é um mecanismo comumente observado nos tumores hipofisários, ao menos para explicar a gênese destes tumores. Aneuploidia pode ser parcialmente explicada em função da hiperexpressão da proteína PTTG (pituitary tumor transforming gene). O cDNA do PTTG foi isolado em células tumorais hipofisárias de ratos (16), tendo seu correspondente humano sido clonado logo a seguir (17). O PTTG hiperexpressa-se em tumores hipofisários humanos, visto que nos adenomas secretores ocorre correlação entre a sua expressão e a agressividade tumoral (18).

Durante a divisão celular, as duas cromátides que se separarão indo cada uma para uma célula filha, estão ligadas por meio de coesinas. Estas serão degradadas pelas separinas ao sinal do término da metáfase. $\mathrm{O}$ PTTG codifica a securina humana, que atua ligando-se e inibindo as separinas (19) e impedindo a proteólise prematura das coesinas (Figura 2). Portanto, a hiperexpressão do PTTG promove aneuploidia, inibindo a segregação das cromátides e aumentando o número de células aneuplóides, levando, assim, à instabilidade genômica (20). Esta proteína não é expressa em tecidos hipofisários normais, demonstrando, portanto, a presença de um gene transformador específico nestes adenomas (18). O PTTG estimula a expressão do FGF (fibroblast growth factor-2), que, por sua vez, está implicado na tumorigênese hipofisária pelo seu efeito promotor de angiogênese e mitogênese. Por outro lado, o FGF também leva à superexpressão do PTTG, o que significa que o aumento da expressão de um gene acaba levando ao aumento na expressão de ambos, constituindo, assim, um mecanismo de retroalimentação positiva. Existe associação funcional direta entre o PTTG, o FGF e a angiogênese, sugerindo que a transativação do FGF pelo PTTG pode causar aumento da vascularização de tumores hipofisários (21).

Em tumores hipofisários têm-se observado maior expressão de ciclinas A, B, D e E quando comparados ao tecido hipofisário normal, sobretudo em tumores maiores e de comportamento agressivo (22).

O nível de expressão da proteína p27, observada em diversas neoplasias, é menor do que o observado em células normais, sugerindo que esta proteína possa atuar como supressor tumoral e ter um fator prognóstico significativo (23). Diversos trabalhos avaliaram a expressão da proteína p27 em tumores hipofisários por meio de imunoistoquímica e observaram nível de expressão menor do que o observado em tecido normal (24-26). Níveis de RNAm entre tumores hipofisários e tecido normal são semelhantes (25) e mutações no gene da proteína p27 não foram observadas $(27,28)$. Estes dados sugerem que a inativação do $p 27$ por mecanismos traducionais ou pós-traducionais tenha papel na patogênese de tumores hipofisários com possível contribuição na progressão para comportamento agressivo. Entretanto, um recente trabalho descreve a mutação germinativa, tipo nonsense, em heterozigose no códon 76 do gene que codifica a proteína p27, em paciente com tumor hipofisário e das paratireóides, sem mutação no gene MEN1. Esta mutação leva à perda de função, já que perde a capacidade de ser transferida ao núcleo, onde é requerida para se ligar ao complexo ciclina-cinase e inibir a progressão do ciclo celular. Este achado suporta a hipótese de papel supressor tumoral para esta proteína (29).

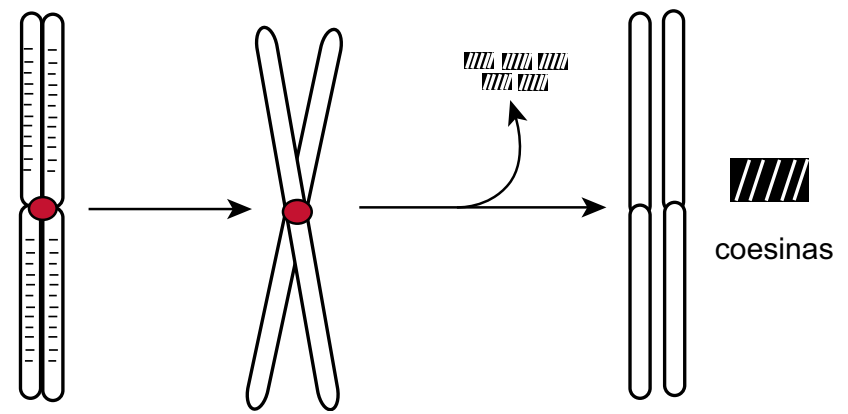

Figura 2. Durante a mitose, as duas cromátides vão se separar indo cada uma para uma célula filha. Estas cromátides estão ligadas por coesinas. Estas serão degradadas pelas separinas ao sinal do término da metáfase. O PTTG codifica a securina humana, que atua ligando-se e inibindo as separinas e impedindo a proteólise prematura das coesinas, inibindo a segregação das cromátides e levando a aneuploidia e à instabilidade genômica. 
A expressão do gene $p 16$, localizado na região $9 \mathrm{p} 21$, encontra-se diminuída nos tumores hipofisários e esta diminuição é em razão de um estado de hipermetilação na região promotora deste gene $(30,31)$. Apesar de não haverem sido identificadas mutações no gene $p 16, \mathrm{LOH}$ no lócus 9p21, foi encontrada em tumores hipofisários, demonstrando que outro gene desta região possa estar envolvido na tumorigênese hipofisária (32).

\section{ONCOGENES}

Também participam da transformação maligna os precursores celulares dos oncogenes, os proto-oncogenes, que codificam proteínas intimamente envolvidas na regulação da proliferação e diferenciação celular (33). Os proto-oncogenes podem ser ativados constitutivamente, seja por rearranjo cromossômico, por amplificação gênica ou por presença de mutações de ponto. Uma vez adquiridas estas alterações os proto-oncogenes passam a ser chamados oncogenes e determinam ganho funcional em células transformadas.

Além disso, células tumorais podem gerar seus próprios sinais estimulatórios de proliferação para deixar $\mathrm{o}$ estado de quiescência e iniciar o processo proliferativo e, dessa forma, mostram reduzida dependência de fatores estimulatórios exógenos, como a produção de fator de crescimento derivado das plaquetas (PDGF) ou do fator de crescimento tumoral $\alpha$ (TGF- $\alpha$ ) nos glioblastomas e sarcomas, respectivamente (2). Por outro lado, muitos oncogenes atuam mimetizando sinalização de crescimento normal. A proteína Ras é uma proteína pertencente à superfamília das proteínas G (ligadora de GTP) que ativam ou inibem moléculas seqüenciais de uma cascata de reações, quando ligadas ao GTP. As formas mutadas desta proteína se ligam com eficiência ao GTP, gerando constantemente sinais estimulatórios, resultando proliferação celular descontrolada (34). Receptores acoplados à proteína $\mathrm{G}$ compreendem uma grande família de receptores de membrana que regulam muitas funções celulares, incluindo proliferação, sobrevivência e mobilidade, e têm recentemente emergido como peças-chave em crescimento tumoral, angiogênese e metástase (35). Embora alguns tumores endócrinos tenham origem em formas mutantes ativadoras de receptores acoplados à proteína $\mathrm{G}$, a expressão anormal destes receptores e sua ativação autócrina e parácrina por agonistas liberados pelas células tumorais representam a forma tática mais freqüente utilizada pelas células tumorais para estimular os receptores acoplados à proteína G e sua rede sinalizadora (35).

\section{GENES SUPRESSORES TUMORAIS}

Genes supressores tumorais, como os genes do retinoblastoma $(R b)$ e o gene supressor tumoral $p 53$, por outro lado, podem inibir o processo de proliferação celular (36). As proteínas codificadas por estes genes estão envolvidas na repressão do crescimento e divisão celular. Alterações nestes genes são freqüentemente observadas em neoplasias humanas e incluem mutações de ponto e perda de heterozigose $(\mathrm{LOH})$.

A partir da observação de famílias portadoras de retinoblastoma, Knudson desenvolveu uma hipótese para explicar a ocorrência de tumores familiares, que se tornou paradigma na compreensão da progressão tumoral (37). Mesmo quando se herda um dos alelos do gene supressor mutado, o alelo normal é capaz de proteger o organismo do desenvolvimento tumoral. O processo tumorigênico só ocorrerá pela perda ou pela inativação do alelo normal, ocorrência eventual durante a proliferação celular (37). Assim, a inativação de um gene supressor tumoral obedece ao modelo de dois eventos (two hits), ou seja, a presença de uma mutação germinativa e de um segundo evento, caracterizado por uma mutação somática ou perda do alelo normal (37) (Figura 3).

O gene supressor tumoral $p 53$ tem papel relevante na progressão tumoral, agindo como fator de transcrição de genes que atuam em resposta a uma variedade de insultos à célula, regulando o ciclo celular ou bloqueando a replicação celular anormal e a transformação maligna. As células que apresentam o gene $p 53$ mutado e, conseqüentemente, inativação da proteína P53 não sofrem este bloqueio. Dessa forma, estas células, geneticamente instáveis, tendem a acumular mutações e rearranjos cromossômicos adicionais, levando à rápida proliferação de clones de células alteradas, contribuindo, assim, para a transformação neoplásica.

Quando o reparo do DNA é finalizado, a proteína P53 ativa a transcrição de seu próprio inibidor, a proteína $\mathrm{Mdm} 2$, de $90 \mathrm{kDa}$, identificada como produto do oncogene mdm2, que, sob ubiquitinação, transporta a proteína P53 para o citoplasma, onde é degradada (38). Alguns oncogenes podem estimular a transcrição de proteínas que se ligam à $\mathrm{Mdm} 2$ e inibir sua atividade (39). Se o reparo do DNA não for satisfatório, a proteína P53 dispara o mecanismo de morte celular programada, a apoptose (40), induzindo a expressão da proteína pró-apoptótica Bax (4l) e inibindo a expressão da proteína antiapoptótica $\mathrm{Bcl}-2$ (42). A inativação 

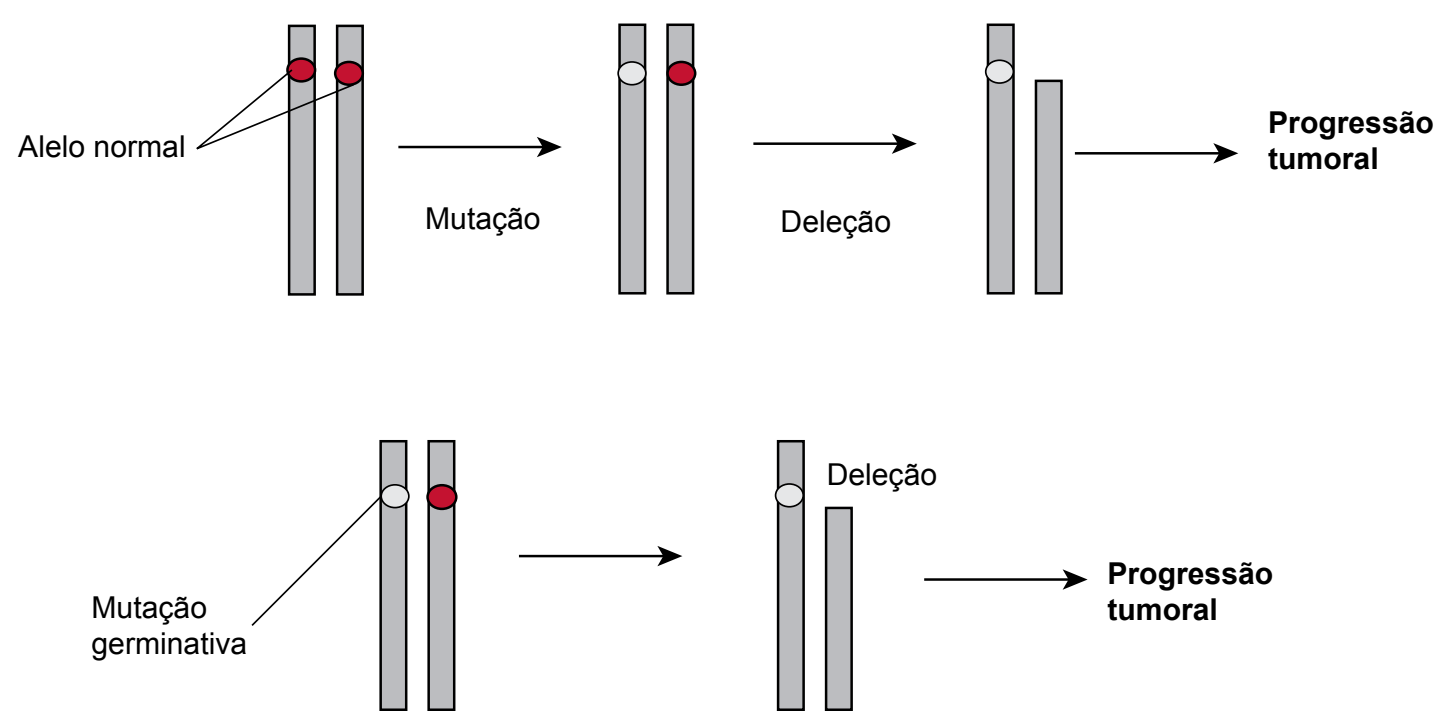

Figura 3. O modelo que explica o desenvolvimento de neoplasias a partir de dois eventos mutacionais complementares $e$ independentes foi descrito por Knudson. Este modelo sugere que para a perda de função dos genes supressores tumorais as duas cópias do gene devem ser inativadas. Freqüentemente, observa-se mutação em um alelo (mutação germinativa) e perda do alelo remanescente (mutação somática) no tecido-alvo. Este fenômeno é descrito como perda de heterozigose.

funcional do gene $p 53$ constitui um mecanismo que garante à célula tumoral evadir-se do processo de apoptose, garantindo a proliferação de células que não sofreram reparo do material genético.

LOH no lócus RBl (13q14) tem sido demonstrada em tumores hipofisários de comportamento agressivo, entretanto, mutações no gene $R B I$ não foram encontradas nestes casos, sugerindo a existência de outro gene de supressão tumoral nesta região (43). Outros genes de supressão tumoral, como os genes NM23 e $B R C A 2$, não parecem estar envolvidos na tumorigênese corticotrófica $(44,45)$. LOH nos loci lp, 3p, 10q26, 11 q13 e 22 q12 têm sido descrita em alguns carcinomas corticotróficos (46).

A metilação (mecanismo epigenético de silenciamento transcricional) em células tumorais desativa genes que normalmente evitariam divisões celulares impróprias. Dessa forma, a metilação pode também explicar a inativação de genes supressores tumorais, ocorrendo, por exemplo, com o gene $p 16^{\mathrm{INK} 4 \mathrm{a}}$, em tumores de pulmão, mama, próstata e rim (47).

A aquisição de resistência à apoptose, morte celular programada é outra característica inerente a vários tipos de tumores. Os mecanismos apoptóticos constituem uma barreira para a progressão tumoral e a célula cancerosa deve evadir-se deste processo (2).
Mutações podem ocorrer continuamente durante a divisão celular e os proto-oncogenes e os genes supressores tumorais não são mais sujeitos a elas que os demais genes. Tendo sido estabelecida a alteração genética, seja por ativação de oncogenes ou inativação de genes supressores tumorais e, por conseguinte, a instabilidade genômica, alterações adicionais se acumulam mais facilmente.

\section{FATORES DE CRESCIMENTO}

O envolvimento de fatores de crescimento no processo de tumorigênese, como EGF (epidermal growth factor), FGF-2 e 4, podem, por meio da família de receptores da tirosino-quinase, influenciar na regulação e na diferenciação celular $(48,49)$. Verificou-se que alguns destes fatores podem, juntamente com seus receptores, ser expressos em tumores hipofisários (Tabela 1).

\section{TUMORES HIPOFISÁRIOS}

Tumores hipofisários pertencem ao grupo de tumores heterogêneos que, em vista da similaridade fisiopatológica, exibem diferentes qualidades dependendo do seu tipo funcional. Alguns são secretores e outros são clini- 
Tabela 1. Agentes implicados na tumorigênese hipofisária.

\begin{tabular}{|c|c|}
\hline Alterações cromossômicas & Forma tumoral \\
\hline Ganho de cromossomos & $\begin{array}{l}\text { Tumores não-funcionantes } \\
\text { Corticotrofinomas e somatotrofinomas }\end{array}$ \\
\hline Perda de cromossomos & Prolactinomas \\
\hline \multicolumn{2}{|l|}{ Oncogenes } \\
\hline Ras & Prolactinomas \\
\hline gsp & Somatotrofinomas; corticotrofinomas; tumores não-funcionantes \\
\hline PTTG & $\begin{array}{l}\text { Somatotrofinomas; prolactinomas; corticotrofinomas; } \\
\text { tumores não-funcionantes }\end{array}$ \\
\hline Ciclina $\mathrm{E}$ & Corticotrofinomas \\
\hline Ciclina D1 & Corticotrofinomas \\
\hline FGFR4 & Prolactinomas \\
\hline \multicolumn{2}{|l|}{ Supressores fumorais } \\
\hline $11 q 13$ & $\begin{array}{l}\text { Somatotrofinomas; prolactinomas; corticotrofinomas; } \\
\text { tumores não-funcionantes }\end{array}$ \\
\hline $13 q 14$ & Somatotrofinomas; prolactinomas; tumores não-funcionantes \\
\hline p53 & Corticotrofinomas \\
\hline \multicolumn{2}{|l|}{ Fatores de crescimento } \\
\hline EGF & Somatotrofinomas \\
\hline FGF2 & Prolactinomas \\
\hline FGF4 & Prolactinomas \\
\hline
\end{tabular}

camente não-funcionantes. Entre os secretores, os prolactinomas são os mais freqüentes. Além disso, cada tipo de tumor pode expressar características variáveis em diferentes pacientes ( 1 ).

\section{Tumores somatotróficos}

Os somatotrófos compreendem cerca de $40 \%$ das células adenohipofisárias. A hipersecreção de hormônio de crescimento $(\mathrm{GH})$ leva a quadro clínico de acromegalia e/ou gigantismo. A síntese e a secreção do $\mathrm{GH}$ são moduladas pelo GHRH, cujo receptor pertence à família dos receptores acoplados à proteína $\mathrm{G}$. Mutações de ponto da subunidade $\alpha$ da proteína G (detectadas em cerca de um terço destes tumores) podem levar à ativação constitutiva (ligante independente) do receptor, com elevação do cAMP e hipersecreção de GH (50). Estas mutações ocorrem em um subgrupo de adenomas somatotróficos, com prevalência variável: $10 \% \mathrm{em}$ japoneses, $30 \%$ a $40 \%$ em caucasianos e coreanos (51). Recentemente, uma mutação somática (histidina/leucina) no códon 49 do domínio extracelular do receptor de $\mathrm{GH}$ foi identificada em um subtipo morfológico de somatotrofos (49).

Em estudos de alterações cromossômicas por CGH, ganho de material cromossômico, em especial do cro- mossomo 19, onde se localiza o gene que codifica a subunidade gama do NGF (nerve growth factor), foi observado grande parte destes tumores, assim como perda do cromossomo 13q (52). A expressão diminuída de NM23 (purine-binding factor) se correlaciona com fenótipo invasivo destes tumores (44). A expressão aumentada do PTTG também se correlaciona com o grau de invasão dos adenomas somatotróficos (51).

Nestes tumores também se observa maior nível de expressão do RNAm (RNA mensageiro) do EGF-R (epidermal growth factor - receptor) (48). Este achado também é observado em tumores de pacientes acromegálicos com recidiva, sugerindo que o EGF possa estar relacionado com a agressividade de tumores hipofisários, particularmente os secretores de GH (51).

\section{Somatotrofinomas de ocorrência familiar}

A acromegalia/gigantismo pode ocorrer associada a duas síndromes familiares: MENl (neoplasia endócrina múltipla) e CNC (complexo de Carney). A MENl é uma síndrome autossômica dominante caracterizada por tumores em paratireóide, pâncreas endócrino e adenohipófise. Os adenomas hipofisários ocorrem em cerca de metade destes pacientes, sendo o prolactinoma o subtipo mais freqüente, seguido pelo somatotrofinoma (53). 
Esta síndrome é causada por mutações no gene $M E N 1$, localizado na região cromossômica $1 \mathrm{lq} 13$. O produto deste gene é a proteína nuclear menin, que parece estar envolvida na regulação de fatores de transcrição, como o JunD e da proteína supressora de metástase Nm23. O CNC é caracterizado pela associação de manifestações diversas, como mixomas (cardíaco, de pele, de mama), pigmentação mucocutânea, tumores adrenais (displasia nodular pigmentada), tireoidianos, testiculares e hipofisários. Os somatotrofinomas, geralmente macroadenomas, estão presentes em $10 \%$ a $21 \%$ dos pacientes portadores do $\mathrm{CNC}$, podendo estar associados a gigantismo ou acromegalia (54). O defeito genético do CNC foi mapeado por análise de ligação aos cromossomos 2p15-16 e 17q23-24 em diferentes famílias $(55,56)$. Curiosamente, pacientes com acromegalia familiar isolada (não ligada a MEN 1) também podem apresentar perda de heterozigose na região $11 \mathrm{q} 13$, mas nestes casos não foram detectadas mutações do gene menin (57). Dessa forma, é provável que mutação em um outro gene próximo ao lócus MEN 1 possa estar envolvida.

Recentemente, mutações envolvendo o gene AIP (aryl hydrocarbon receptor interacting protein), que mapeia a região $1 \mathrm{lql} 3$, foram associadas à predisposição familial a adenomas hipofisários. O total de 14 mutações germinativas neste gene foi reportado, e entre estas foi observada a mutação Y268X em uma situação de acromegalia familiar, envolvendo quatro membros, em população brasileira (58). Em outro estudo, multicêntrico, envolvendo nove países (inclusive o Brasil), foi analisada a freqüência de mutações no gene AIP em 73 famílias com FIPA (familial isolated pituitary adenomas), sendo identificados 156 indivíduos com adenomas hipofisários. Em 11 destas 73 famílias, foram observadas 10 diferentes mutações no gene AIP (Q142X, Q217X, Q239X, R304X, R16H, R271W, K24lE, G47_R54del, E174fs e Q285fs), indicando que mutações neste gene ocorrem em uma pequena proporção de famílias com FIPA (15\%) (59). Para acessar dados genéticos e clínicos em família portadora de mutações no gene AIP foi conduzido um estudo em uma família brasileira composta de 122 membros, ao longo de seis gerações, para rastreamento de portadores da mutação E174fs. Os portadores desta mutação (10 casos) foram submetidos à análise clínica, hormonal e radiológica. Apenas três dos 10 indivíduos apresentavam tumores hipofisários, indicando baixa penetrância para tumores hipofisários $(33,3 \%)$ em portadores de mutação no gene AIP. Um paciente apresentava MRI normal, telarca prematura, ovários desenvolvidos e idade óssea avançada na ausência de outras causas subjacentes, sugerindo que mutações neste gene podem ir além da tumorigênese hipofisária (60).

\section{Prolactinomas}

Os adenomas produtores de prolactina são os mais prevalentes entre os adenomas hipofisários secretores e também os mais comuns (> 50\%) entre os tumores da hipófise associados a MENl. No entanto, a ocorrência de prolactinomas familiares isolados não é tão bem estabelecida como no caso do acrogigantismo (61). Os mecanismos que levam ao desenvolvimento dos adenomas lactotróficos não são bem estabelecidos. Entre os mais relacionados estão o PTTG e o HST (heparin-binding secretory transforming gene), ambos provavelmente atuando por intermédio de fatores de crescimento de fibroblastos (FGF-2 e FGF-4, respectivamente) induzindo angiogênese (62). Os estrógenos parecem exercer papel fundamental nestes mecanismos, já que drogas com ação antiestrogênica inibem a expressão do PTTG em prolactinomas in vitro e o seu crescimento in vivo (63). Recentemente, vários estudos têm demonstrado o desenvolvimento de prolactinomas em camundongos com knock-out do receptor D2 (dopamine receptor), sendo este fenótipo mais intenso e de mais rápida evolução nas fềmeas e nos animais tratados com estrogênios. No entanto, até o presente não foram encontradas mutações no gene do receptor D2 (64). Outros mecanismos potencialmente envolvidos na tumorigênese dos prolactinomas são a redução na expressão de LIF (leukemia inhibitory factor) (65) e de NGF (nerve growth factor) (66). O BMP-4 (bone morphogenetic protein-4), membro da família de TGF $\beta$ é hiperexpresso em diferentes modelos de prolactinomas. A proteína SMAD, ativada pelos fatores de crescimento, tanto TGF quanto BMP, interage com os receptores de estrógenos para estimular a proliferação de células secretoras de prolactina e de GH (67). Em relação a outros fatores relacionados à agressividade dos prolactinomas, somente uma mutação do gene H-ras em um prolactinoma invasivo foi descrita em estudos que examinaram mais de 200 adenomas hipofisários secretores e não-secretores. Adicionalmente, tal mutação foi encontrada em metástase de carcinoma lactotrófico, mas não no tumor primitivo (51). Prolactinomas resistentes aos agonistas dopaminérgicos, como a bromocriptina, têm freqüentemente comportamento agressivo, podendo ser inclusive malignos. No entanto, pouco se conhece quanto ao mecanismo desta resistência além da redução da densidade dos receptores dopa- 
minérgicos da classe D2 e da redução da relação entre a isoforma curta (D2S) e a isoforma longa (D2L) destes receptores.

Em estudos de alterações cromossômicas por CGH, perda de material cromossômico, em especial do cromossomo 11, onde se localiza o gene para o receptor de dopamina (D2R) (68). Os prolactinomas associados à síndrome de neoplasia endócrina múltipla tipo 1 (NEM1), que apresentam perda de heterozigose no lócus $11 q 13$ e mutações no gene menin, tendem a ser mais agressivos do que os prolactinomas esporádicos. É interessante ressaltar que cerca de $15 \%$ dos prolactinomas esporádicos apresentam perda de heterozigose $1 \mathrm{lql}$, mas sem mutações detectadas no gene que codifica a "menin".

\section{Tumores corticotróficos}

As células produtoras de hormônio adrenocorticotrófico (ACTH) constituem $15 \%$ a $20 \%$ da população adenohipofisária. Cerca de 10\% a 15\% dos adenomas hipofisários são representados pelos corticotrófos, grande parte constituído por microadenomas. Embora 5\% destes sejam silenciosos, a maior parte hipersecreta ACTH, levando à doença de Cushing, causa mais freqüente de hipercortisolismo. Do ponto de vista de sua etiopatogenia, não se conhece a razão da maior parte destes tumores serem microadenomas. A participação hipotalâmica deve ser considerada na progressão para adenomas mais agressivos, já que cerca de $30 \%$ dos pacientes tratados por adrenalectomia bilateral desenvolvem tumores invasivos (síndrome de Nelson) por perderem o efeito frenador dos níveis elevados de cortisol sobre o eixo CRH-ACTH, não mantido pelas doses de reposição de corticosteróides naturais ou sintéticos. É justamente o fato de os adenomas corticotróficos manterem semelhanças de retroalimentação com o corticotrofo normal, em nível mais elevado, que torna o estudo destes tumores muito atraente para o entendimento do processo de oncogênese: pode-se inferir que o defeito somático que ocorre no clone corticotrófico seja sutil.

Existem defeitos comuns com outros tipos tumorais hipofisários: mutações ativadoras da proteína $\mathrm{G}$ são descritas em cerca de 6\% dos adenomas corticotróficos. Também podem estar associados a MENl, embora com freqüência menor do que os prolactinomas e somatotrofinomas. Neste tipo tumoral também se observa a hiperexpressão de PTTG. Em estudos de alterações cromossômicas por CGH ganho de mate- rial cromossômico, em especial do cromossomo 19, onde se localiza o gene que codifica a ciclina $\mathrm{E}$ (que é normalmente hiperexpresso nestes tumores), foi observado em grande parte deles $(68,69)$. Dois supressores tumorais também estão envolvidos na tumorigênese dos corticotrófos: os inibidores do complexo ciclina-cinase p27 e p16. A ausência da proteína p27 está relacionada à sua rápida degradação $(70)$ e em relação à proteína pl6, a ausência da proteína funcional é associada à metilação do seu gene (71).

\section{Hiperexpressão dos receptores de $\mathrm{CRH}$ e de vasopressina (V3R)}

Tanto o CRH (corticotropin-releasing hormone) quanto a vasopressina estimulam a liberação de ACTH. Estudos recentes demonstram que adenomas corticotróficos exibem hiperexpressão nos receptores de $\mathrm{CRH}$ (CRH-R) e do subtipo 3 da vasopressina (V3R) em comparação com corticotrofos normais, sendo ambos os receptores da família da proteína G. No entanto, não foram detectadas mutações nas regiões codificadoras dos genes CRH-R e V3R, fato que não aponta para ativação constitutiva da transdução do sinal. Assim, não está claro se a hiperexpressão destes receptores atua como causa de tumorigênese corticotrófica, ou seja, conseqüência do hipercortisolismo decorrente destes tumores $(51)$.

\section{Aumento da expressão do fator inibidor de leucemia (LIF)}

O LIF é membro da família das citoquinas que incluem, entre outras, as interleucinas 1 e 6 . Induz, atuando por meio de receptor próprio (LIF-R), a secreção de ACTH, e potencializa os efeitos do CRH. Estudos têm sugerido participação do LIF na diferenciação do corticotrofo. Recentemente foram demonstrados hiperplasia corticotrófica e fenótipo cushingóide em camundongos transgênicos hiperexpressando LIF. No entanto, não está clara a participação desta citoquina na tumorigênese corticotrófica (5l).

\section{Receptor de glicocorticóides (GR)}

Mutações no gene que codifica o GR (glucocorticoid receptor) levando à alteração na sua função poderiam contribuir para a resistência relativa aos glicocorticóides verificada nos adenomas corticotróficos. No entanto, com exceção do tecido tumoral de um paciente com síndrome de Nelson, não foram verificadas muta- 
ções no gene do GR em outros pacientes com esta síndrome, e em portadores de doença de Cushing, inclusive em um caso de carcinoma produtor de ACTH (51). Estes dados sugerem que mutações no gene do GR não são comumente envolvidas na tumorigênese corticotrófica. Entretanto, estudo recente sugere que deleções neste gene podem influir na etiopatogenia da doença de Cushing: 30\% dos tumores corticotróficos examinados para perda de heterozigose em cinco polimorfismos conhecidos do gene do GR apresentavam deleções monoalélicas. O significado funcional destas deleções nestes tumores não foi estabelecido, já que não foram encontradas mutações no outro alelo e não foram efetuados estudos de expressão para caracterizar a haploinsuficiência do GR (51). Um recente estudo da expressão do EGFR (epidermal growth factor receptor) em tumores hipofisários verificou que a maior expressão deste receptor foi detectada em adenomas corticotróficos. É possível que o envolvimento do EGFR na tumorigênese corticotrófica se faça por meio da redução de expressão da proteína p27.

\section{Tumores clinicamente não-funcionantes}

Os tumores clinicamente não-funcionantes representam cerca de $30 \%$ a $40 \%$ dos tumores hipofisários e constituem classe heterogênea dentro destes, já que, mesmo sem secretar quantidades apreciáveis de hormônios adenohipofisários, podem imunoexpressá-los. A maior parte dos adenomas clinicamente não-secretores é composta por gonadotrofinomas, mesmo aqueles que não apresentam imunoexpressão hormonal (null cell adenomas) são provavelmente de linhagem gonadotrófica; estudos de hibridação in situ mostram que estes tumores freqüentemente expressam o RNAm do hormônio folículo estimulante (FSH)/hormônio luteinizante (LH), e muitos deles secretam subunidade $\alpha$, parte da molécula comum aos hormônios gonadotróficos. Existem descrições de mutações ativadoras na proteína $\mathrm{G}$ em adenomas não-funcionantes, assim como perda alélica envolvendo a região 11 ql3 (51).

Observa-se, nestes tumores, elevada expressão de PTTG (1). Curiosamente, ao contrário dos prolactinomas e somatotrofinomas, não há correlação entre a expressão do PTTG e o grau de invasibilidade dos adenomas não secretores estudados. Em estudos de alterações cromossômicas por CGH, anormalidades genéticas foram observadas na maioria dos tumores analisados, sendo ganho do cromossomo $\mathrm{X}$ identificado em um substancial número de tumores $(68,72)$. A expressão aumentada da ciclina Dl também é observada neste tipo tumoral (73).

\section{CONCLUSÕES}

Os tumores hipofisários exibem uma variedade de modelos de proliferação e comportamento hormonal. Estes tumores exibem origem monoclonal e o mecanismo sugerido para a formação do tumor envolve fatores genéticos intrínsecos. Entretanto, alterações genéticas envolvendo oncogenes e genes supressores tumorais têm sido identificadas em uma pequena minoria dos tumores hipofisários isolados, e estas incluem mutações no oncogene gsp, expressão aumentada de PTTG e inativação de genes supressores tumorais nas regiões $11 \mathrm{ql} 3$ e 13q. Instabilidade cromossômica é padrão constante do processo tumorigênico e uma ligação pode ser feita entre este fenômeno e a expressão aumentada de PTTG, ambos claramente demonstrados em diversas formas de tumores hipofisários.

\section{REFERÊNCIAS}

1. Sonabend AM, Musleh W, Lesniak MS. Oncogenesis and mutagenesis of pituitary tumors. Expert Rev Anticancer Ther. 2006;6 Suppl 9:S3-14.

2. Hanahan D, Weinberg RA. The hallmarks of cancer. Cell. 2000;100(1):57-70.

3. Cairns J. The origin of human cancers. Nature. 1981;289 (5796):353-7.

4. Renan MJ. How many mutations are required for tumorigenesis? Implications from human cancer data. Mol Carcinog. 1993;7(3):139-46.

5. Harley $C B$, Futcher $A B$, Greider $C W$. Telomeres shorten during ageing of human fibroblasts. Nature. 1990;345(6274):458-60.

6. Bodnar AG, Ouellette M, Frolkis M, Holt SE, Chiu CP, Morin $\mathrm{GB}$, et al. Extension of life-span by introduction of telomerase into normal human cells. Science. 1998;279(5349):349-52.

7. Maser RS, DePinho RA. Connecting chromosomes, crisis, and cancer. Science. 2002;297(5581):565-9.

8. Bishop JM. Viral oncogenes. Cell. 1985;42(1):23-38.

9. Herman V Fagin J, Gonsky R, Kovacs K, Melmed S. Clonal origin of pituitary adenomas. J Clin Endocrinol Metab. 1990;71(6):1427-33.

10. Asa SL, Ezzat S. The cytogenesis and pathogenesis of pituitary adenomas. Endocr Rev. 1998;19(6):798-827.

11. Lyon MF. Gene action in the X-chromosome of the mouse (Mus musculus L.). Nature. 1961;190:372-3.

12. Elledge SJ. Cell cycle checkpoints: preventing an identity crisis. Science. 1996;274(5293):1664-72.

13. Albrechtsen N, Dornreiter I, Grosse F, Kim E, Wiesmüller L, Deppert W. Maintenance of genomic integrity by p53: complementary roles for activated and non-activated p53. Oncogene. 1999;18(53):7706-17.

14. El-Deiry WS. p21/p53, cellular growth control and genomic integrity. Curr Top Microbiol Immunol. 1998;227:121-37. 
15. Kastan MB, Onyekwere O, Sidransky D, Vogelstein B, Craig RW. Participation of p53 protein in the cellular response to DNA damage. Cancer Res. 1991;51(23 Pt 1):6304-11.

16. Pei L, Melmed S. Isolation and characterization of a pituitary tumor-transforming gene (PTTG). Mol Endocrinol. 1997;11(4):433-41.

17. Zhang $X$, Horwitz GA, Prezant TR, Valentini A, Nakashima M, Bronstein MD, Melmed S. Structure, expression, and function of human pituitary tumor-transforming gene (PTTG). Mol Endocrinol. 1999;13(1):156-66.

18. Zhang $X$, et al. Pituitary tumor transforming gene (PTTG) expression in pituitary adenomas. J Clin Endocrinol Metab. 1999;84(2):761-7.

19. Zou H Horwitz GA, Heaney AP, Nakashima M, Prezant TR, Bronstein MD, Melmed S. Identification of a vertebrate sisterchromatid separation inhibitor involved in transformation and tumorigenesis. Science. 1999;285(5426):418-22.

20. Yu R, Lu W, Chen J, McCabe CJ, Melmed S. Overexpressed pituitary tumor-transforming gene causes aneuploidy in live human cells. Endocrinology. 2003;144(11):4991-8.

21. McCabe CJ, Khaira JS, Boelaert K, Heaney AP, Tannahill LA, Hussain $\mathrm{S}$, et al. Expression of pituitary tumour transforming gene (PTTG) and fibroblast growth factor-2 (FGF-2) in human pituitary adenomas: relationships to clinical tumour behaviour. Clin Endocrinol (Oxf). 2003;58(2):141-50.

22. Turner HE, Nagy Z, Sullivan N, Esiri MM, Wass JA. Expression analysis of cyclins in pituitary adenomas and the normal pituitary gland. Clin Endocrinol (Oxf). 2000;53(3):337-44.

23. Nickeleit I Zender S, Kossatz U, Malek NP. p27kip1: a target for tumor therapies? Cell Div. 2007;2:13.

24. Lloyd RV Jin L, Qian X, Kulig E. Aberrant p27kip1 expression in endocrine and other tumors. Am $J$ Pathol. 1997;150(2):401-7.

25. Jin L, Qian X, Kulig E, Sanno N, Scheithauer BW, Kovacs K, et al. Transforming growth factor-beta, transforming growth factor-beta receptor II, and p27Kip1 expression in nontumorous and neoplastic human pituitaries. Am J Pathol. 1997;151(2):509-19.

26. Bamberger A, Sudahl S, Bamberger CM, Schulte HM, Löning T. Expression patterns of the cell-cycle inhibitor p27 and the cell-cycle promoter cyclin $E$ in the human placenta throughout gestation: implications for the control of proliferation. Placenta. 1999;20(5-6):401-6.

27. Tanaka C, Yoshimoto K, Yang P, Kimura T, Yamada S, Moritani $M$, et al. Infrequent mutations of p27Kip1 gene and trisomy 12 in a subset of human pituitary adenomas. J Clin Endocrinol Metab. 1997; 82(9):3141-7.

28. Dahia PL, Aguiar RC, Honegger J, Fahlbush R, Jordan S, Lowe DG, et al. Mutation and expression analysis of the p27/kip1 gene in corticotrophin-secreting tumours. Oncogene. 1998;16(1):69-76.

29. Pellegata NS, Quintanilla-Martinez L, Siggelkow $H$, Samson E, Bink K, Höfler H, et al. Germ-line mutations in p27Kip1 cause a multiple endocrine neoplasia syndrome in rats and humans. Proc Natl Acad Sci U S A. 2006;103(42):15558-63.

30. Seemann N, Kuhn D, Wrocklage C, Keyvani K, Hackl W, Buchfelder M, et al. CDKN2A/p16 inactivation is related to pituitary adenoma type and size. J Pathol. 2001;193(4):491-7.

31. Jaffrain-Rea ML, Ferretti E, Toniato E, Cannita K, Santoro A, Di Stefano D, et al. p16 (INK4a, MTS-1) gene polymorphism and methylation status in human pituitary tumours. Clin Endocrinol (Oxf). 1999;51(3):317-25.
32. Yoshimoto K, Tanaka C, Yamada S, Kimura T, Iwahana H, Sano $\mathrm{T}$, Itakura M. Infrequent mutations of p16INK4A and p15INK4B genes in human pituitary adenomas. Eur $\mathrm{J}$ Endocrinol. 1997;136(1):74-80.

33. Bishop JM. Molecular themes in oncogenesis. Cell. 1991;64(2):235-48.

34. Medema $\mathrm{RH}$, de Vries-Smits AM, van der Zon GC, Maassen JA, Bos JL. Ras activation by insulin and epidermal growth factor through enhanced exchange of guanine nucleotides on p21ras. Mol Cell Biol. 1993;13(1):155-62.

35. Dorsam RT, Gutkind JS. G-protein-coupled receptors and cancer. Nat Rev Cancer. 2007;7(2):79-94.

36. Marshall CJ. Tumor suppressor genes. Cell. 1991. 64(2):313-26.

37. Knudson AG. Hereditary cancer: two hits revisited. J Cancer Res Clin Oncol. 1996;122(3):135-40.

38. Meng RD, Shih H, Prabhu NS, George DL, el-Deiry WS. Bypass of abnormal MDM2 inhibition of p53-dependent growth suppression. Clin Cancer Res. 1998;4(1):251-9.

39. Vogelstein B, Lane D, Levine AJ. Surfing the p53 network. Nature. 2000;408(6810):307-10.

40. Morgan SE, Kastan MB. p53 and ATM: cell cycle, cell death and cancer. Adv Cancer Res. 1997;71:1-25.

41. Miyashita T, Krajewski S, Krajewska M, Wang HG, Lin HK, Liebermann DA, et al. Tumor suppressor p53 is a regulator of bcl-2 and bax gene expression in vitro and in vivo. Oncogene. 1994;9(6):1799-805.

42. Janus F, Albrechtsen N, Dornreiter I, Wiesmüller L, Grosse F, Deppert $W$. The dual role model for p53 in maintaining genomic integrity. Cell Mol Life Sci. 1999;55(1):12-27.

43. Donangelo I, Araújo PB, Antenuzi D, Farage M, Marcondes J, Filho PN, Gadelha MR. Tumor deletion mapping of chromosomal region $13 q 14$ in 43 growth hormone secreting pituitary adenomas. Endocrine. 2005;28(2):131-6.

44. Takino H, Herman V, Weiss M, Melmed S. Purine-binding factor (nm23) gene expression in pituitary tumors: marker of adenoma invasiveness. J Clin Endocrinol Metab. 1995;80(5):1733-8.

45. Pearce SH, Trump D, Wooding C, Sheppard MN, Clayton RN, Thakker RV. Loss of heterozygosity studies at the retinoblastoma and breast cancer susceptibility (BRCA2) loci in pituitary, parathyroid, pancreatic and carcinoid tumours. Clin Endocrinol (Oxf). 1996;45(2):195-200.

46. Bates AS, Buckley N, Boggild MD, Bicknell EJ, Perrett CW, Broome JC, Clayton RN. Clinical and genetic changes in a case of a Cushing's carcinoma. Clin Endocrinol (Oxf). 1995;42(6):663-70; discussion 671-2.

47. Herman JG, Merlo A, Mao L, Lapidus RG, Issa JP, Davidson $\mathrm{NE}$, et al. Inactivation of the CDKN2/p16/MTS1 gene is frequently associated with aberrant DNA methylation in all common human cancers. Cancer Res. 1995;55(20):525-30.

48. LeRiche VK, Asa SL, Ezzat S. Epidermal growth factor and its receptor (EGF-R) in human pituitary adenomas: EGF-R correlates with tumor aggressiveness. J Clin Endocrinol Metab. 1996;81(2):656-62.

49. Abbass SA, Asa SL, Ezzat S. Altered expression of fibroblast growth factor receptors in human pituitary adenomas. J Clin Endocrinol Metab. 1997;82(4):1160-6.

50. Thakker RV, Pook MA, Wooding C, Boscaro M, Scanarini M, Clayton RN. Association of somatotrophinomas with loss of alleles on chromosome 11 and with gsp mutations. J Clin Invest. 1993;91(6):2815-21. 
51. Bronstein MD, Melmed S. Pituitary tumorigenesis. Arq Bras Endocrinol Metabol. 2005;49(5):615-25.

52. Hui AB, Pang JC, Ko CW, Ng HK. Detection of chromosomal imbalances in growth hormone-secreting pituitary tumors by comparative genomic hybridization. Hum Pathol. 1999;30(9):1019-23.

53. Scheithauer BW, Laws ER Jr, Kovacs K, Horvath E, Randall RV, Carney JA. Pituitary adenomas of the multiple endocrine neoplasia type I syndrome. Semin Diagn Pathol. 1987;4(3):205-11.

54. Yen RS, Allen B, Ott R, Brodsky M. The syndrome of right atrial myxoma, spotty skin pigmentation, and acromegaly. Am Heart J. 1992;123(1):243-4.

55. Stratakis CA, Carney JA, Lin JP, Papanicolaou DA, Karl M, Kastner DL, et al. Carney complex, a familial multiple neoplasia and lentiginosis syndrome. Analysis of 11 kindreds and linkage to the short arm of chromosome 2. J Clin Invest. 1996;97(3):699-705.

56. Casey M, Mah C, Merliss AD, Kirschner LS, Taymans SE, Denio $A E$, et al. Identification of a novel genetic locus for familial cardiac myxomas and Carney complex. Circulation. 1998;98(23):2560-6.

57. Gadelha MR, Prezant TR, Une KN, Glick RP, Moskal SF 2nd, Vaisman $M$, et al. Loss of heterozygosity on chromosome $11 q 13$ in two families with acromegaly/gigantism is independent of mutations of the multiple endocrine neoplasia type I gene. J Clin Endocrinol Metab. 1999;84(1):249-56.

58. Toledo RA, Lourenço DM Jr, Liberman B, Cunha-Neto MB, Cavalcanti MG, Moyses CB, et al. Germline mutation in the aryl hydrocarbon receptor interacting protein gene in familial somatotropinoma. J Clin Endocrinol Metab. 2007;92(5):1934-7.

59. Daly AF, Vanbellinghen JF, Khoo SK, Jaffrain-Rea ML, Naves LA, Guitelman MA, et al. Aryl hydrocarbon receptor-interacting protein gene mutations in familial isolated pituitary adenomas: analysis in 73 families. J Clin Endocrinol Metab. 2007;92(5):1891-6.

60. Naves LA, Daly AF, Vanbellinghen JF, Casulari LA, Spilioti C, Magalhães AV, et al. Variable pathological and clinical features of a large Brazilian family harboring a mutation in the aryl hydrocarbon receptor-interacting protein gene. Eur J Endocrinol. 2007;157(4):383-91.

61. Berezin M, Karasik A. Familial prolactinoma. Clin Endocrinol (Oxf). 1995;42(5):483-6.

62. Shimon I, Hinton DR, Weiss MH, Melmed S. Prolactinomas express human heparin-binding secretory transforming gene (hst) protein product: marker of tumour invasiveness. Clin Endocrinol (Oxf). 1998;48(1):23-9.

63. Heaney AP, Fernando M, Melmed S. Functional role of estrogen in pituitary tumor pathogenesis. J Clin Invest. 2002;109(2):277-83.
64. Friedman E, Adams EF, Höög A, Gejman PV, Carson E, Larsson $C$, et al. Normal structural dopamine type 2 receptor gene in prolactin-secreting and other pituitary tumors. J Clin Endocrinol Metab. 1994;78(3):568-74.

65. Ben-Shlomo A, Miklovsky I, Ren SG, Yong WH, Heaney AP, Culler MD, Melmed S. Leukemia inhibitory factor regulates prolactin secretion in prolactinoma and lactotroph cells. J Clin Endocrinol Metab. 2003;88(2):858-63.

66. Missale C, Fiorentini C, Finardi A, Spano P. Growth factors in pituitary tumors. Pituitary. 1999;1(3-4):153-8.

67. Giacomini D, Páez-Pereda M, Theodoropoulou M, Gerez J, Nagashima AC, Chervin A, et al. Bone morphogenetic protein-4 control of pituitary pathophysiology. Front Horm Res. 2006;35:22-31.

68. Trautmann K, Thakker RV, Ellison DW, Ibrahim A, Lees PD, Harding $B$, et al. Chromosomal aberrations in sporadic pituitary tumors. Int J Cancer. 2001;91(6):809-14.

69. Jordan S, Lidhar K, Korbonits M, Lowe DG, Grossman AB. Cyclin D and cyclin E expression in normal and adenomatous pituitary. Eur J Endocrinol. 2000;143(1):R1-6.

70. Bamberger CM, Fehn M, Bamberger AM, Lüdecke DK, Beil FU, Saeger W, Schulte HM. Reduced expression levels of the cellcycle inhibitor p27Kip1 in human pituitary adenomas. Eur $\mathrm{J}$ Endocrinol. 1999;140(3):250-5.

71. Simpson DJ, McNicol AM, Murray DC, Bahar A, Turner HE, et al. Molecular pathology shows p16 methylation in nonadenomatous pituitaries from patients with Cushing's disease. Clin Cancer Res. 2004;10(5):1780-8.

72. Daniely M, Aviram A, Adams EF, Buchfelder M, Barkai G, Fahlbusch $R$, et al. Comparative genomic hybridization analysis of nonfunctioning pituitary tumors. J Clin Endocrinol Metab. 1998;83(5):1801-5.

73. Hibberts NA, Simpson DJ, Bicknell JE, Broome JC, Hoban PR, Clayton RN, Farrell WE. Analysis of cyclin D1 (CCND1) allelic imbalance and overexpression in sporadic human pituitary tumors. Clin Cancer Res. 1999;5(8):2133-9.

\section{Endereço para correspondência:}

Emilia Modolo Pinto

Laboratório de Hormônios e Genética Molecular LIM/42 do HC-FMUSP

Av. Dr. Enéas Carvalho de Aguiar, 155, $2^{\circ}$ andar, bloco 6 05403-900 São Paulo, SP

E-mail: emiliap@plugnet.com.br 